\title{
Prevalence of Chronic Obstructive Lung Disease in Korea Using Data from the Fifth Korea National Health and Nutrition Examination Survey
}

\author{
Hwayeon Park', Se Young Jung ${ }^{1}$, Kiheon Lee ${ }^{1, *}$, Woo Kyung Bae ${ }^{2}$, Keehyuck Lee', Jong-Soo Han², Sarah Kim', \\ Seryung $\mathrm{Choo}^{1}$, Jin-Mook Jeong ${ }^{3}$, Hyun-Ray $\mathrm{Kim}^{3}$, Hyun Jung Ro ${ }^{3}$, Hansol Jeong ${ }^{3}$ \\ 'Department of Family Medicine, Seoul National University College of Medicine and Seoul National University Bundang Hospital, Seongnam, Korea \\ ${ }^{2}$ Department of Family Medicine, Health Promotion Center, Seoul National University College of Medicine and Seoul National University Bundang \\ Hospital, Seongnam, Korea \\ ${ }^{3}$ Department of Family Medicine, Seoul National University Hospital, Seoul, Korea
}

Background: Chronic obstructive pulmonary disease (COPD) is the fifth leading cause of death worldwide. The awareness and treatment rate of the disease are low despite its relatively high prevalence. With the added data, this study aimed to identify changes in prevalence and risk factors of COPD using the data from the 5 th KNHNES.

Methods: The subjects of this study were 8,969 individuals aged 40 and older who satisfied suitability and reproducibility for pulmonary function tests. The prevalence, awareness and risk factors of COPD were predicted based on the questionnaires on gender, age, educational level, income level, smoking history, body mass index (BMI) and other COPD related questions.

Results: Diagnosis of COPD was based on the airflow limitation (forced expiratory volume in one second/forced vital capacity < 0.7) of the Global Initiative for Chronic Obstructive Lung Disease (GOLD) criteria. The prevalence of COPD from 2010 to 2012 was $13.7 \%$, of which $23.3 \%$ was men and $6.5 \%$ women. The prevalence was on the rise, with $12.2 \%$ in 2010, $13.2 \%$ in 2011, and $15.5 \%$ in 2012. In GOLD stage 1, the percentages of those who had cough or sputum and smoking history were $12.1 \%$ and $75.5 \%$, respectively, but only $0.1 \%$ was diagnosed with COPD. Even after adjusting for asthma and tuberculosis, men, old age, larger amount of smoking were linked with a higher prevalence of COPD, and obese and higher educational level were associated with a lower prevalence of COPD.

Conclusion: The prevalence of COPD in Korea has been increasing every year, and a higher prevalence was associated with male, older age, more amount of smoking, lower educational level and lower BMI.

Keywords: Chronic Obstructive Pulmonary Disease; Pulmonary Function Tests; Prevalence; Korea

Received: August 29, 2014, Accepted: March 5, 2015

*Corresponding Author: Kiheon Lee Tel: +82-31-787-7801, Fax: +82-31-787-4078, E-mail: keyhoney@gmail.com

Hwayeon Park and Se Young Jung contributed equally to this work as first authors. 


\section{INTRODUCTION}

Chronic obstructive pulmonary disease (COPD) is a chronic inflammatory disease that causes irreversible airflow limitation in the airways. This disease may be caused by smoking, fumes, a history of occupational exposure, and infection, which damage the pulmonary parenchyma and narrow the airway. The early stage is typically asymptomatic, although coughing, sputum, and shortness of breath become evident as the disease progresses. These conditions lead to respiratory infection and limitations in the patient's daily routine, and ultimately to a lower quality of life. ${ }^{1)}$

The prevalence and mortality of COPD are high worldwide, ${ }^{2)}$ and so are the resultant national and socioeconomic burdens. ${ }^{3)}$ According to the World Health Organization's 2004 estimates, there were 64 million people with COPD worldwide and 3 mil lion people died due to $\mathrm{COPD}^{4)}$ this disease is expected to be the third leading cause of death by 2030 . The Korean National Health and Nutrition Examination Survey (KNHNES) 2008 also reported that approximately $13.4 \%$ of the population who were $\geq 40$ years old exhibited airflow limitation (forced expiratory volume in one second $\left[\mathrm{FEV}_{1}\right] /$ forced vital capacity $[\mathrm{FVC}]$ of $<0.7$ ) during pulmonary function testing. ${ }^{5)}$ In addition, 15.6 of 100,000 persons die because of respiratory diseases, including COPD, ${ }^{6}$ which was the seventh leading cause of death in Korea. ${ }^{7)}$

In Korea, no studies have evaluated the prevalence of COPD since the 4th KNHNES. However, the 5th KNHNES strengthened the diagnostic criterion for COPD, as it required $\geq 3$ appropriate pulmonary function test curves, compared to the previous criterion of $\geq 2$ appropriate curves. Moreover, the 5 th $\mathrm{KN}$ HNES also evaluated for a history of tuberculosis, via chest radiography. Therefore, this study aimed to investigate the prevalence and risk factors for COPD, based on data from the 5th $\mathrm{KN}$ HNES.

\section{METHODS}

Between 2010 and 2012, the 5th KNHNES included 3,800 households within 192 enumeration districts, which were representative of the entire Korean population. Of 12,221 participants who were $\geq 40$ years old, we selected 8,969 individuals for analysis in the present study.

The presence of COPD was based on the airflow limitation criteria $\left(\mathrm{a} \mathrm{FEV}_{1} / \mathrm{FVC}\right.$ of $\left.<0.7\right)$ that were suggested by the Global Initiative for Chronic Obstructive Lung Disease (GOLD). According to the GOLD criteria, the severity of COPD is divided into four stages: stage 1 (mild; $\mathrm{FEV}_{1} \geq 80 \%$ ), stage 2 (moderate; $\mathrm{FEV}_{1}$ 50\%-80\%), stage 3 (severe; $\mathrm{FEV}_{1} 30 \%-50 \%$ ), and stage 4 (very severe; $\mathrm{FEV}_{1}<30 \%$ ).

\section{Definitions of Smokers and Amount of Smoking}

Non-smokers were defined as individuals who had smoked $<100$ cigarettes during their entire life, while smokers were defined as individuals who had smoked $\geq 100$ cigarettes during their entire life. Smokers were divided into former smokers and current smokers, depending on whether they were currently smoking or not. Pack-years was used to calculate the amount of smoking, by multiplying the average number of packs per day by the number of years smoked, regardless of whether the individual was a former or current smoker.

\section{Body Mass Index}

The body mass index (BMI) values were calculated by dividing the individual's body weight by their height squared. A BMI of $<18.5 \mathrm{~kg} / \mathrm{m}^{2}$ was defined as underweight, a BMI of 18.5 to 23 $\mathrm{kg} / \mathrm{m}^{2}$ was defined as normal, a BMI of 23 to $25 \mathrm{~kg} / \mathrm{m}^{2}$ was defined as overweight, and a BMI of $\geq 25 \mathrm{~kg} / \mathrm{m}^{2}$ was defined as obese.

\section{Criteria for Regional Classification, Income, and Educational Level}

The 16 cities and provinces were divided into urban and rural regions. The urban regions included Seoul, Busan, Daegu, Incheon, Gwangju, Daejeon, and Ulsan, and the rural region included all other provinces (including Jeju). Income level was based on quartiles of the raw income data from the 5th KNHNES. Education level was divided into elementary school graduation or lower, middle school graduation, high school graduation, and university graduation or higher. Individuals who had dropped out, enrolled students, and students who were on a leave of absence were included in the lowest education category.

\section{Pulmonary Function Tests}

Of 12,221 participants who were $\geq 40$ years old, pulmonary function testing was performed for 8,969 of the surveyed individuals. The remaining individuals did not consent to participate or were not eligible for the testing $(n=1,742)$, or did not satisfy the requirements for acceptability and repeatability for pulmonary testing $(n=1,510)$. According to the 5 th KNHNES criterion, only patients who provided at least 3 test curves were considered acceptable. We considered repeatability to be satisfactory when the difference between the greatest value and the second greatest values for $\mathrm{FEV}_{1}$ or $\mathrm{FVC}$ was $<150 \mathrm{~mL}$.

\section{Survey}

Before the pulmonary function testing, a survey was administered to individuals who were available for the pulmonary function testing. The survey addressed whether the subjects had been diagnosed with COPD, chronic bronchitis, or emphysema, and also evaluated the presence of respiratory symptoms ("Have you coughed almost every day in at least 3 consecutive 
months during the past year?, Have you coughed up sputum almost every day in at least 3 consecutive months for during the past year?").

\section{Chest Radiography}

The chest radiography results were interpreted by 2 specialists, 1 from the pulmonary medicine department and 1 from the radiology department; their interpretations were then compared. The interpretation results for this study were subsequently reinterpreted by 6 reading doctors. The classifications for tuberculosis included active tuberculosis (TB), suspected TB, and inactive $\mathrm{TB}$, based on the chest radiography interpretations.

\section{Statistical Analysis Methods}

Weighting was applied for the analysis of this study's data. The general characteristics of the subjects (both men and women) were identified using the $t$-test and $\chi^{2}$ test for each variable. Mean, variance, number, and percentage were used to report the data, as appropriate. A multiple logistic regression analysis was performed to identify the independent risk factors for COPD, and the findings were reported as odds ratios (OR) and 95\% confidence interval (CI). Stata software ver. 12.1 (Stata Co., College Station, TX, USA) was used for all analyses.

\section{RESULTS}

Among the 8,969 individuals who were included in our analysis, the mean age was 55.7 years (men 54.8 years, women 56.6 years); the men were significantly younger than the women $(\mathrm{P}<0.001)$. The study included 3,867 men and 5,102 women, although there was no significant sex-related difference regarding region $(\mathrm{P}=0.24)$ and income level $(\mathrm{P}=0.77)$. The frequency of non-smokers (54.7\%) was higher than that of smokers $(45.3 \%)$. The amount of smoking was greatest in men with a longer smoking period, although the amount of smoking was greatest among women with $<10$ pack-years $(5.7 \%)$ (Table 1$)$.

\section{Prevalence of Chronic Obstructive Pulmonary Disease according to the Amount of Smoking and Age}

The prevalence of COPD increased every year from 2010 to

Table 1. Characteristics of the study sample with valid spirometry data $(n=8,969)$

\begin{tabular}{|c|c|c|c|c|}
\hline Characteristic & Men $(n=3,867)$ & Women $(n=5,102)$ & Total $(\mathrm{n}=8,969)$ & P-value \\
\hline $\operatorname{Age}^{*}(\mathrm{y})$ & $54.8 \pm 10.2$ & $56.5 \pm 12.1$ & $55.7 \pm 11.2$ & $<0.001^{\dagger}$ \\
\hline Age group (y) & & & & $<0.001^{\ddagger}$ \\
\hline $40-49$ & $1,158(38.5)$ & $1,369(34.1)$ & 2,527 (36.2) & \\
\hline $50-59$ & $1,147(31.1)$ & $1,673(29.1)$ & $2,820(30.1)$ & \\
\hline $60-69$ & 954 (17.5) & $1,260(17.6)$ & $2,214(17.6)$ & \\
\hline$\geq 70$ & $608(13.0)$ & 800 (19.2) & $1,408(16.2)$ & \\
\hline Education & & & & $<0.001^{\ddagger}$ \\
\hline Elementary school & $758(19.5)$ & $2,028(40.1)$ & $2,786(30.2)$ & \\
\hline Middle school & $609(16.0)$ & 795 (14.9) & $1,404(15.4)$ & \\
\hline High school & $1,325(36.0)$ & $1,539(31.2)$ & $2,864(33.5)$ & \\
\hline College/university & $1,175(28.5)$ & $740(13.9)$ & $1,915(20.9)$ & \\
\hline Region & & & & $0.24^{\ddagger}$ \\
\hline Urban & $1,713(43.0)$ & $2,334(44.4)$ & $4,047(43.7)$ & \\
\hline Rural & $2,154(57.0)$ & 2,768 (55.6) & 4,922 (56.3) & \\
\hline Income level $\left.\right|^{\S}$ & & & & $0.77^{\ddagger}$ \\
\hline 1st quartile & $837(25.6)$ & $1,189(26.2)$ & 2,026 (25.9) & \\
\hline 2nd quartile & $974(26.1)$ & 1,252 (26.2) & $2,226(26.1)$ & \\
\hline 3rd quartile & $1,020(25.5)$ & $1,305(24.5)$ & $2,325(25.0)$ & \\
\hline 4th quartile & $1,036(22.9)$ & $1,356(23.1)$ & $2,392(23.0)$ & \\
\hline Smoking status & & & & $<0.001^{\ddagger}$ \\
\hline Never & $595(14.2)$ & 4,742 (91.8) & $5,337(54.7)$ & \\
\hline Former & $1,847(44.0)$ & $159(3.6)$ & $2,006(22.9)$ & \\
\hline Current & $1,425(42.0)$ & $201(4.6)$ & $1,626(22.4)$ & \\
\hline Smoking amount" & & & & $<0.001^{\ddagger}$ \\
\hline$<10$ pack-year & $639(15.8)$ & $243(5.7)$ & $882(10.5)$ & \\
\hline 10-19 pack-year & 738 (19.3) & $69(1.6)$ & $807(10.0)$ & \\
\hline 20-29 pack-year & $778(21.4)$ & $23(0.4)$ & $801(10.4)$ & \\
\hline$\geq 30$ pack-year & $1,117(29.4)$ & $25(0.5)$ & $1,142(14.3)$ & \\
\hline Body mass index $\left(\mathrm{kg} / \mathrm{m}^{2}\right)$ & & & & $<0.001^{\ddagger}$ \\
\hline Underweight (<18.5) & $39(1.2)$ & $78(1.6)$ & $117(1.4)$ & \\
\hline Normal (18.5-22.9) & $1,190(30.3)$ & $1,840(35.9)$ & $3,028(33.2)$ & \\
\hline Overweight (23-24.9) & $1,130(28.6)$ & $1,348(25.3)$ & $2,481(26.9)$ & \\
\hline Obesity $(\geq 25)$ & $1,501(40.0)$ & $1,845(37.2)$ & $3,343(38.5)$ & \\
\hline
\end{tabular}

Values are presented as number (\%), unless otherwise indicated.

${ }^{*}$ Subjects are greater than 40 years of age, mean \pm SD. ${ }^{\dagger}$ Chi-square test for categorical variables. ${ }^{*}$ By t-test for continuous variables. ${ }^{8}$ Data from the 5 th Korea National Health and Nutritional Examination Survey. "Includes former and current smokers. 
2012 (Figure 1), and the average prevalence of COPD for the three years was $13.7 \%$ (men $23.3 \%$, women $6.5 \%$ ). The prevalence increased with lower educational levels in both men and women ( $\mathrm{P}$ for trend $<0.001$ ). Smokers had a higher prevalence of COPD, compared to non-smokers, among both men and women. The prevalence increased with greater smoking amounts, as airflow limitation was found in $57.6 \%$ of men and $54.4 \%$ of women with $\geq 20$ pack-years ( $\mathrm{P}$ for trend $<0.001$ ) (Table 2 ). In addition, the prevalence of COPD increased with age in both

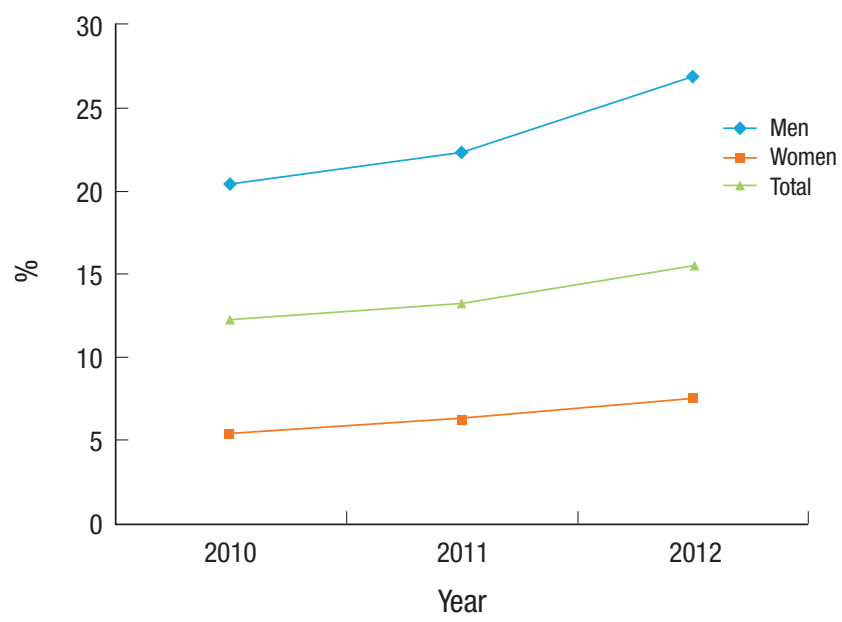

Figure 1. Annual prevalence of airflow obstruction according to year and sex. men and women ( $\mathrm{P}$ for trend $<0.001$ ), and was especially high $(53.6 \%)$ among men who were $\geq 70$ years old (Figure 2 ).

\section{Respiratory Symptoms, Smoking, and Detection Rate according to Chronic Obstructive Pulmonary Disease Severity}

Among the 8,969 individuals, the prevalence of GOLD stage 1 was $6.5 \%$, GOLD stage 2 was $6.6 \%$, GOLD stage 3 was $0.5 \%$, and GOLD stage 4 was $0.1 \%$. Among the subjects who were diag-

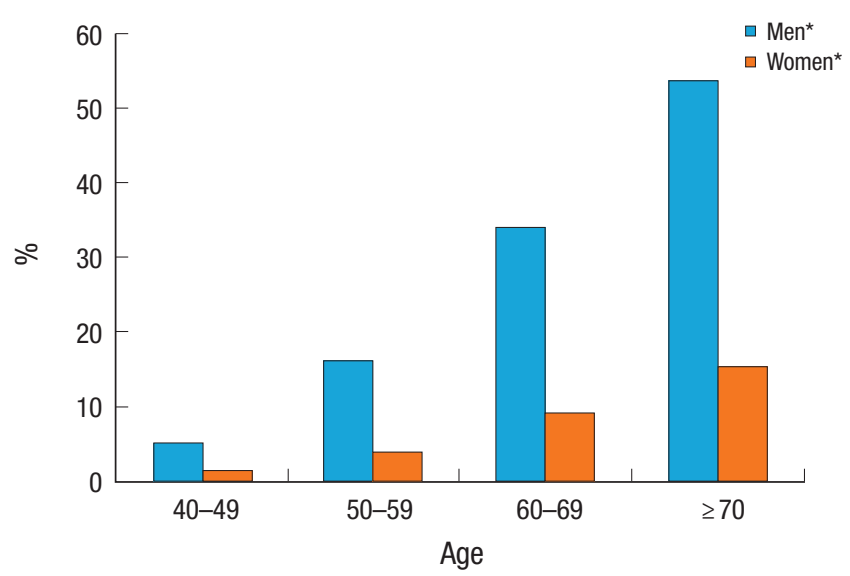

Figure 2. Stratified prevalence of airflow obstruction according to sex and age. *P for trend $<0.001$

Table 2. Prevalence of airway obstruction according to the GOLD criteria*

\begin{tabular}{|c|c|c|c|c|c|c|c|c|c|}
\hline \multirow[b]{2}{*}{ Characteristic } & \multicolumn{3}{|c|}{ Men } & \multicolumn{3}{|c|}{ Women } & \multicolumn{3}{|c|}{ Total population } \\
\hline & $\begin{array}{c}\text { No. of } \\
\text { subjects }^{\dagger}\end{array}$ & $\begin{array}{l}\text { Prevalence } \\
(\%)\end{array}$ & P-value & $\begin{array}{c}\text { No. of } \\
\text { subjects }^{\dagger}\end{array}$ & $\begin{array}{c}\text { Prevalence } \\
(\%)\end{array}$ & P-value & $\begin{array}{c}\text { No. of } \\
\text { subjects }\end{array}$ & $\begin{array}{l}\text { Prevalence } \\
(\%)\end{array}$ & P-value \\
\hline Age ( $\geq 40 y)$ & 899 & 23.3 & & 331 & 6.5 & & 1,230 & 13.7 & \\
\hline $\begin{array}{l}\text { Education } \\
\text { Elementary school } \\
\text { Middle school } \\
\text { High school } \\
\text { College/university }\end{array}$ & $\begin{array}{l}306 \\
174 \\
273 \\
146\end{array}$ & $\begin{array}{l}40.4 \\
28.6 \\
20.6 \\
12.4\end{array}$ & $<0.001^{\ddagger}$ & $\begin{array}{r}216 \\
37 \\
55 \\
23\end{array}$ & $\begin{array}{r}10.7 \\
4.7 \\
3.6 \\
3.1\end{array}$ & $<0.001^{\ddagger}$ & $\begin{array}{l}522 \\
211 \\
328 \\
169\end{array}$ & $\begin{array}{r}18.7 \\
15.0 \\
11.5 \\
8.8\end{array}$ & $<0.001^{\ddagger}$ \\
\hline $\begin{array}{l}\text { Region } \\
\text { Urban } \\
\text { Rural }\end{array}$ & $\begin{array}{l}403 \\
496\end{array}$ & $\begin{array}{l}23.5 \\
23.1\end{array}$ & 0.74 & $\begin{array}{l}135 \\
196\end{array}$ & $\begin{array}{l}5.8 \\
7.1\end{array}$ & 0.06 & $\begin{array}{l}538 \\
692\end{array}$ & $\begin{array}{l}13.3 \\
14.1\end{array}$ & 0.29 \\
\hline $\begin{array}{l}\text { Income level| }^{\S} \\
\text { 1st quartile } \\
\text { 2nd quartile } \\
\text { 3rd quartile } \\
\text { 4th quartile }\end{array}$ & $\begin{array}{l}202 \\
244 \\
241 \\
213\end{array}$ & $\begin{array}{l}24.1 \\
25.1 \\
23.6 \\
20.6\end{array}$ & $0.04^{\ddagger}$ & $\begin{array}{l}76 \\
91 \\
80 \\
84\end{array}$ & $\begin{array}{l}6.4 \\
7.3 \\
6.1 \\
6.2\end{array}$ & $0.56^{\ddagger}$ & $\begin{array}{l}278 \\
334 \\
321 \\
297\end{array}$ & $\begin{array}{l}13.7 \\
15.0 \\
13.8 \\
12.4\end{array}$ & $0.1^{\ddagger}$ \\
\hline $\begin{array}{l}\text { Smoking status } \\
\text { Never } \\
\text { Former } \\
\text { Current }\end{array}$ & $\begin{array}{r}87 \\
476 \\
336\end{array}$ & $\begin{array}{l}14.6 \\
25.8 \\
23.6\end{array}$ & 0.00 & $\begin{array}{r}285 \\
18 \\
28\end{array}$ & $\begin{array}{r}6.0 \\
11.3 \\
13.9\end{array}$ & $<0.001$ & $\begin{array}{l}372 \\
494 \\
364\end{array}$ & $\begin{array}{r}7.0 \\
24.6 \\
22.4\end{array}$ & $<0.001$ \\
\hline $\begin{array}{l}\text { Smoking amount" } \\
\text { <10 pack-year } \\
\text { 10-19 pack-year } \\
\text { 20-29 pack-year } \\
\geq 30 \text { pack-year }\end{array}$ & $\begin{array}{l}101 \\
144 \\
176 \\
391\end{array}$ & $\begin{array}{l}15.8 \\
19.5 \\
22.6 \\
35.0\end{array}$ & $<0.001^{\ddagger}$ & $\begin{array}{r}26 \\
7 \\
7 \\
6\end{array}$ & $\begin{array}{l}10.7 \\
10.1 \\
30.4 \\
24.0\end{array}$ & $0.01^{\ddagger}$ & $\begin{array}{l}127 \\
151 \\
183 \\
397\end{array}$ & $\begin{array}{l}14.4 \\
18.7 \\
22.9 \\
34.8\end{array}$ & $<0.001^{\ddagger}$ \\
\hline
\end{tabular}

GOLD, Global Initiative for Chronic Obstructive Lung Disease.

${ }^{*}$ GOLD criteria: forced expiratory volume in one second/forced vital capacity ratio $<0.7$. ${ }^{\dagger}$ No. of subjects who have airway obstruction in spirometry. ${ }^{*}$ Data from the 5 th Korea National Health and Nutritional Examination Survey. IIncludes former and current smokers. "P-value is for trend. 
Table 3. Stratified prevalence of airflow obstruction and frequencies of risk factors according to the GOLD criteria

\begin{tabular}{|c|c|c|c|c|c|}
\hline \multirow{2}{*}{ Variable } & \multicolumn{4}{|c|}{ GOLD criteria* } & \multirow{2}{*}{$\begin{array}{c}\text { Total } \\
(n=1,230)\end{array}$} \\
\hline & $1(n=583)$ & $2(n=597)$ & $3(n=44)$ & $4(n=6)$ & \\
\hline Prevalence $^{\dagger}$ & 6.5 & 6.7 & 0.5 & 0.1 & 13.7 \\
\hline Cough & 3.3 & 5.4 & 28.3 & 14.1 & 5.5 \\
\hline Sputum & 11.9 & 14.2 & 35.7 & 14.1 & 14.1 \\
\hline Cough or sputum & 12.1 & 14.6 & 39.1 & 28.3 & 14.6 \\
\hline Smoking ${ }^{\ddagger}$ & 75.5 & 70.2 & 68.5 & 61.3 & 72.5 \\
\hline \multicolumn{6}{|l|}{ Smoking amount ${ }^{\ddagger}$} \\
\hline$<20$ pack-year & 25.3 & 21.2 & 17.1 & 14.1 & 22.9 \\
\hline$\geq 20$ pack-year & 50.2 & 48.9 & 51.4 & 47.2 & 49.6 \\
\hline Doctor-diagnosed chronic obstructive pulmonary disease & 0.1 & 2.3 & 29.8 & 27.4 & 2.6 \\
\hline
\end{tabular}

Values are presented as \%.
GOLD, Global Initiative for Chronic Obstructive Lung Disease; FEV ${ }_{1}$, forced expiratory volume in one second; FVC, forced vital capacity.

${ }^{*} \mathrm{GOLD} 1, \mathrm{FEV} / \mathrm{FVC}<0.70$ and $\mathrm{FEV}_{1} \geq 80 \%$ of the predicted value; GOLD 2, FEV $/$ FVC $<0.70$ and $\mathrm{FEV}_{1} 50 \%-80 \% ; \mathrm{GOLD} 3, \mathrm{FEV} / / \mathrm{FVC}<0.70$ and FEV $130 \%-50 \%$; GOLD 4 ,

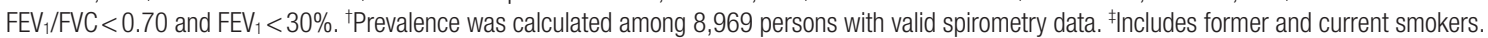

Table 4. Multivariate analysis of the risk factors for chronic obstructive pulmonary disease

\begin{tabular}{|c|c|c|}
\hline Characteristic & $\begin{array}{l}\text { Adjusted odds ratio } \\
\text { (95\% confidence interval) }\end{array}$ & P-value* \\
\hline \multicolumn{3}{|l|}{ Sex } \\
\hline Female & 1 & \\
\hline Male & $2.86(2.04-3.99)$ & $<0.001$ \\
\hline \multicolumn{3}{|l|}{ Age (y) } \\
\hline $40-64$ & 1 & \\
\hline$\geq 65$ & $4.20(3.44-5.14)$ & $<0.001$ \\
\hline \multicolumn{3}{|l|}{ Region } \\
\hline Urban & 1 & \\
\hline Rural & $0.88(0.72-1.08)$ & 0.02 \\
\hline \multicolumn{3}{|l|}{ Education } \\
\hline Elementary school & 1 & \\
\hline Middle school & $0.72(0.55-0.95)$ & 0.02 \\
\hline High school & $0.54(0.43-0.69)$ & $<0.001$ \\
\hline College/university & $0.34(0.25-0.46)$ & $<0.001$ \\
\hline \multicolumn{3}{|l|}{ Income $^{\dagger}$} \\
\hline 1st quartile & 1 & \\
\hline 2nd quartile & $1.20(0.97-1.49)$ & 0.10 \\
\hline 3rd quartile & $0.98(0.77-1.26)$ & 0.90 \\
\hline 4th quartile & $1.07(0.84-1.36)$ & 0.61 \\
\hline \multicolumn{3}{|l|}{ Smoking amount } \\
\hline Never & 1 & \\
\hline$<20$ pack-year & $1.77(1.28-2.44)$ & 0.00 \\
\hline$\geq 20$ pack-year & $3.29(2.40-4.51)$ & $<0.001$ \\
\hline \multicolumn{3}{|l|}{ Asthma } \\
\hline No & 1 & \\
\hline Yes & 4.05 (2.82-5.82) & $<0.001$ \\
\hline \multicolumn{3}{|l|}{ Tuberculosis $^{\ddagger}$} \\
\hline No & 1 & \\
\hline Yes & $3.20(2.50-4.11)$ & $<0.001$ \\
\hline \multicolumn{3}{|l|}{ Body mass index $\left(\mathrm{kg} / \mathrm{m}^{2}\right)$} \\
\hline Underweight $(<18.5)$ & 1 & \\
\hline Normal (18.5-22.9) & $0.46(0.26-0.83)$ & 0.01 \\
\hline Overweight (23-24.9) & $0.38(0.21-0.70)$ & 0.00 \\
\hline Obesity ( $\geq 25)$ & $0.28(0.16-0.51)$ & $<0.001$ \\
\hline
\end{tabular}

${ }^{*}$ Calculated using multiple logistic regression analysis. ${ }^{+}$Data from the 5 th Korea National Health and Nutritional Examination Survey. FHistory of tuberculosis is defined using chest radiography.

nosed with COPD, the prevalence of GOLD stage 1 was $47.4 \%$, GOLD stage 2 was $48.5 \%$, GOLD stage 3 was $3.6 \%$, and GOLD stage 4 was $0.5 \%$.
The incidences of at least 1 symptom of cough or sputum in Gold stages 1 and 2 were $12.1 \%$ and $14.6 \%$, respectively, compared to $39.1 \%$ and $28.3 \%$ in GOLD stages 3 and 4 . In GOLD stage $1,75.5 \%$ of the individuals had a past or current history of smoking. The prevalences of COPD diagnosis, including emphysema and chronic bronchitis, were $0.1 \%, 2.3 \%, 29.8 \%$, and $27.4 \%$ for GOLD stages 1-4, respectively (Table 3 ).

\section{Risk Factors for Chronic Obstructive Pulmonary Disease} After adjusting for asthma and tuberculosis, the multiple regression analysis revealed that COPD occurred significantly more frequently in men (OR, 2.86; CI, 2.04 to 3.99), older individuals (OR, 4.20; CI, 3.44 to 5.14), and in individuals with high smoking amounts (OR, 3.29; CI, 2.40 to 4.51). However, COPD occurred significantly less frequently in individuals with a high educational level (OR, 0.34; CI, 0.25 to 0.46) and a high BMI (OR, 0.28; CI, 0.16 to 0.51$)$. Region $(\mathrm{P}=0.22)$ and income level $(\mathrm{P}=0.1,0.9$, 0.61) had no significant relationship with the prevalence of COPD after adjusting for other risk factors (Table 4).

\section{DISCUSSION}

In the 5th KNHNES (2010-2012), the prevalence of COPD among individuals who were $\geq 40$ years old was $13.7 \%$ (men $23.3 \%$, women $6.5 \%$ ). The prevalence increased from $12.2 \%$ in 2010 to $13.2 \%$ in 2011 and $15.5 \%$ in 2012.

Smoking and age are widely known as major risk factors for $\mathrm{COPD},{ }^{8)}$ and we found that the prevalences among current smokers $(22.4 \%)$ and former smokers $(24.6 \%)$ were higher than the prevalence among non-smokers (7.0\%). In addition, the prevalence of COPD was higher in men, even after adjusting for smoking status and the amount of smoking (OR, 2.86; CI, 2.04 to 3.99). It has been suggested that the sex-related differences in prevalence are attributable to the sex-related differences in sensitivity to smoking-related lung damage ${ }^{9)}$ and sex-related differences in airway anatomy. ${ }^{10)}$ However, a recent study has sug- 
gested that no sex-related differences in prevalence was found in advanced countries. ${ }^{8)}$ Therefore, further studies are needed to evaluate sex as a risk factor for COPD.

In this study, COPD occurred more frequently in urban areas (compared to rural areas), although this difference was not statistically significant $(\mathrm{P}=0.22)$; previous similar studies have reported varying results. For example, the prevalence of COPD was significantly higher in a rural area during a comparative study of geriatric diseases in rural and urban area of Korea ${ }^{11)}$ and during the 3rd National Health and Nutrition Examination Survey in the US. ${ }^{12)}$ The study regarding the prevalence of COPD using the KNHNES 2001 data suggested that rural areas had a higher prevalence, although this finding was not statistically significant. ${ }^{6)}$ These discrepancies appear to be due to the fact that it is difficult to identify risk factors within a region, because people in rural areas are relatively old and exposed more to chemicals or pesticides, while people in urban areas are exposed to more air pollution, such as car fumes and dust.

Few studies have examined the relationship between obesity and COPD. One study has reported that people with higher BMI had better pulmonary function. ${ }^{13)}$ This finding was attributed to the fact that emphysema becomes worse in individuals who are underweight (compared to obese individuals with the same amount of smoking), as chronic malnutrition can cause emphysema in the pulmonary parenchyma. However, in the present study, we found that obese individuals exhibited a significantly lower prevalence of COPD (compared to underweight individuals), after adjusting for age, sex, smoking, and educational level (OR, 0.28; CI, 0.16 to 0.51). Therefore, further studies regarding this relation are needed.

Among 1,230 individuals with COPD, 95.9\% were in GOLD stages 1 and 2, and the percentages of people with symptoms of cough or sputum for more than 3 months in each stage were $12.1 \%$ and $14.6 \%$, respectively. In addition, their smoking rates were $75.5 \%$ and $70.2 \%$, although only $0.1 \%$ and $2.3 \%$, respectively, had doctor-diagnosed COPD. Therefore, it is likely that most individuals who were in GOLD stages 1 and 2 with airflow limitation were not diagnosed with COPD, despite their high rates of smoking and respiratory symptoms, which represents missed opportunities for appropriate treatments. This may be because awareness of COPD is low, due to the lack of information regarding the disease, which precludes appropriate diagnosis and treatment. As patients with COPD are predominantly elderly individuals, they may also recognize the disease as 'lung disease, 'asthma, or 'tuberculosis,' due to the disease's ambiguity. Therefore, it is likely that the detection rate for COPD is low, due to the difficulty in differentiating it from other lung diseases, despite the prevalence increasing with age.

The low awareness of COPD is a significant factor in the progression of the disease. During the mild stage, shortness of breath occurs while exercising ${ }^{14)}$ and mortality increases, ${ }^{15)}$ with acute exacerbation and mortality increasing significantly in the later stages. ${ }^{16)}$ Although there is controversy regarding whether treatment in the mild or moderate stages significantly reduces mortality, it has been reported that treatment can improve pulmonary function and acute exacerbation. ${ }^{17,18)}$ In addition, providing low-risk COPD patients with education regarding smoking, immunization, exercise, medication, symptoms, and treatment resulted in reduced hospitalization due to acute exacerbation. ${ }^{19)}$ Therefore, it is expected that early detection and education can improve patients' quality of life, and reduce the socioeconomic costs that are associated with COPD. ${ }^{20)}$

We found that $50.2 \%$ and $48.9 \%$ of individuals with mild and moderate airflow limitations, respectively, had $\geq 20$ pack-years. In addition, individuals with $\geq 20$ pack-years exhibited a 3 -fold greater prevalence of COPD compared to non-smoking individuals (OR, 3.20; CI, 2.50 to 4.11), after adjusting for sex and age. Therefore, men who are $\geq 40$ years old with heavy smokers, and have respiratory symptoms should likely undergo pulmonary function testing to screen for the early detection of COPD.

The strengths of this study include the increased diagnostic criterion, which may provide a more accurate diagnosis, compared to that in previous studies. This is because the 5 th $\mathrm{KNH}$ NES strengthened the standards for acceptability, by requiring $\geq 3$ appropriate pulmonary function tests, compared to the previous standard of 2 appropriate pulmonary function tests. In addition, previous studies have not considered a history of tuberculosis, although this condition can affect the pulmonary function test results. ${ }^{21)}$ Therefore, we adjusted for the effects of tuberculosis by analyzing chest radiography findings.

The limitations of this study are that it was difficult to differentiate COPD from asthma, because a bronchodilator was not used for the pulmonary function testing. Therefore, we cannot exclude the possibility of asthma and COPD overlap syndrome. ${ }^{22)}$ Furthermore, thorough instructions must be provided to individuals during the testing, as numerous individuals were excluded from the study due to improper pulmonary function test results.

In conclusion, the prevalence of COPD in Korea increased from $12.2 \%$ in 2010 to $13.2 \%$ in 2011 and $15.5 \%$ in 2012 . In addition, the prevalence of COPD was significantly higher among men, older individuals, individuals with a high smoking amount, individuals with a low educational level, and individuals with a low BMI.

\section{CONFLICT OF INTEREST}

No potential conflict of interest relevant to this article was reported.

\section{REFERENCES}

1. Leidy NK, Haase JE. Functional performance in people with chronic 
obstructive pulmonary disease: a qualitative analysis. ANS Adv Nurs Sci 1996;18:77-89.

2. Calverley PM, Walker P. Chronic obstructive pulmonary disease. Lancet 2003;362:1053-61.

3. Sullivan SD, Ramsey SD, Lee TA. The economic burden of COPD. Chest 2000;117(2 Suppl):5S-9S.

4. World Health Organization. Chronic obstructive pulmonary disease (COPD) fact sheet no. 315 [Internet]. Geneva: World Health Organization; 2013 [cited Nov 17 2014]. Available from: http://www.who.int/ mediacentre/factsheets/fs315/en/.

5. Yoo KH, Kim YS, Sheen SS, Park JH, Hwang YI, Kim SH, et al. Prevalence of chronic obstructive pulmonary disease in Korea: the fourth Korean National Health and Nutrition Examination Survey, 2008. Respirology 2011;16:659-65.

6. Kim DS, Kim YS, Jung KS, Chang JH, Lim CM, Lee JH, et al. Prevalence of chronic obstructive pulmonary disease in Korea: a population-based spirometry survey. Am J Respir Crit Care Med 2005;172:842-7.

7. Statistics Korea. Korea National Statistical Office [Internet]. Daejeon: Statistics Korea; 2012 [cited Nov 17 2014]. Available from: http://kostat. go.kr/wnsearch/search.jsp.

8. Mannino DM, Buist AS. Global burden of COPD: risk factors, prevalence, and future trends. Lancet 2007;370:765-73.

9. Sorheim IC, Johannessen A, Gulsvik A, Bakke PS, Silverman EK, DeMeo DL. Gender differences in COPD: are women more susceptible to smoking effects than men? Thorax 2010;65:480-5.

10. Kim YI, Schroeder J, Lynch D, Newell J, Make B, Friedlander A, et al. Gender differences of airway dimensions in anatomically matched sites on CT in smokers. COPD 2011;8:285-92.

11. Rhee HS, Hwang EJ, Hong MH. A comparative study of geriatric disease in rural and urban areas. Korean J Fam Med 1991;12:36-46.

12. Hnizdo E, Sullivan PA, Bang KM, Wagner G. Airflow obstruction attributable to work in industry and occupation among U.S. race/ethnic groups: a study of NHANES III data. Am J Ind Med 2004;46:126-35.

13. Cecere LM, Littman AJ, Slatore CG, Udris EM, Bryson CL, Boyko EJ, et al. Obesity and COPD: associated symptoms, health-related quality of life, and medication use. COPD 2011;8:275-84.

14. Ofir D, Laveneziana P, Webb KA, Lam YM, O’Donnell DE. Mechanisms of dyspnea during cycle exercise in symptomatic patients with GOLD stage I chronic obstructive pulmonary disease. Am J Respir Crit Care Med 2008;177:622-9.

15. Mannino DM, Doherty DE, Sonia Buist A. Global Initiative on Obstructive Lung Disease (GOLD) classification of lung disease and mortality: findings from the Atherosclerosis Risk in Communities (ARIC) study. Respir Med 2006;100:115-22.

16. Hurst JR, Vestbo J, Anzueto A, Locantore N, Mullerova H, Tal-Singer R, et al. Susceptibility to exacerbation in chronic obstructive pulmonary disease. N Engl J Med 2010;363:1128-38.

17. Jenkins CR, Jones PW, Calverley PM, Celli B, Anderson JA, Ferguson GT, et al. Efficacy of salmeterol/fluticasone propionate by GOLD stage of chronic obstructive pulmonary disease: analysis from the randomised, placebo-controlled TORCH study. Respir Res 2009;10:59.

18. Decramer M, Celli B, Kesten S, Lystig T, Mehra S, Tashkin DP, et al. Effect of tiotropium on outcomes in patients with moderate chronic obstructive pulmonary disease (UPLIFT): a prespecified subgroup analysis of a randomised controlled trial. Lancet 2009;374:1171-8.

19. Siddique HH, Olson RH, Parenti CM, Rector TS, Caldwell M, Dewan NA, et al. Randomized trial of pragmatic education for low-risk COPD patients: impact on hospitalizations and emergency department visits. Int J Chron Obstruct Pulmon Dis 2012;7:719-28.

20. Boland MR, Tsiachristas A, Kruis AL, Chavannes NH, Rutten-van Molken MP. The health economic impact of disease management programs for COPD: a systematic literature review and meta-analysis. BMC Pulm Med 2013;13:40.

21. Jordan TS, Spencer EM, Davies P. Tuberculosis, bronchiectasis and chronic airflow obstruction. Respirology 2010;15:623-8.

22. Gibson PG, Simpson JL. The overlap syndrome of asthma and COPD: what are its features and how important is it? Thorax 2009;64:728-35. 